\title{
Taking the Orient Express
}

\author{
Lars W. van den Hoek Ostende ${ }^{1}$ (D) $\cdot$ Serdar Mayda $^{2}$ (I) $\cdot$ Tanju Kaya $^{3}$ \\ Published online: 21 November 2019 \\ (C) Senckenberg Gesellschaft für Naturforschung and Springer-Verlag GmbH Germany, part of Springer Nature 2019
}

Certainly in the first years of its existence, the Orient Express formed for western travellers the gateway to the east. The famous railroad was in those days, before the foundation of the modern Turkish Republic, very much a journey to mysticism. No doubt, Agatha Christie's "Murder on the Orient Express" added to the fame of the luxury train, that in its heydays took travellers from Paris to Istanbul. And hers not the only title inspired by this railroad.

Also the third meeting of the Working Group Terrestrial Ecosystems of the Regional Committee for Mediterranean Neogene Stratigraphy (RCMNS) flirted in his main title with the nostalgia of the nineteenth century train. 'Taking the Orient Express, the role of Anatolia in the Mediterranean Neogene palaeobiogeography' was a three-day congress held between 16th and 18th of September 2016 at the Natural History Museum of EGE University in Izmir. In understanding the palaeobiogeography of Europe, Anatolia is of pivotal importance because of its central position between Europe, Asia and Africa. Mammal taxa migrating into Europe, for which there are scores of examples, followed pretty much the same route as the iconic railway. Moreover, the Orient Express was a means for people from the east and west to meet each other, as was the purpose of the workshop. Much as for the first railroad travellers, Anatolia is for modern day palaeontologists a place of discovery, with new faunas and new taxa being discovered every year. And as in the days of old, the only way of truly understanding the region is by joining with the people who know the country best, the colleagues who spent their entire career in Turkey. And thus,

This is the editorial to the special issue "Taking the Orient Express? The role of Anatolia in mediterranean Neogene palaeobiogeography"

Lars W. van den Hoek Ostende

Lars.vandenhoekostende@ naturalis.nl

1 Naturalis Biodiversity Center, Darwinweg 2, 2333, CR Leiden, The Netherlands

2 Faculty of Science, Biology Department, Ege University, Bornova, Izmir, Turkey

3 Natural History Museum, Ege University, Bornova, Izmir, Turkey scientists from seven different European countries joined their Turkish colleagues in Izmir for what would turn out to be a very successful workshop (Fig. 1). Some of the results of that meeting are presented in this special issue of Palaeobiodiversity and Palaeoenvironments.

\section{The venue}

The meeting took place in the second largest natural history museum of Turkey. The Natural History Museum of EGE University was founded in 1973 by palaeontologist Fikret Ozansoy, one of the most renowned palaeontologists of his day. The collection houses thousands of fossils of mammals from all over Turkey, testifying of the importance of Anatolia in the terrestrial ecosystems of, in particular, the Neogene. Particularly at the end of the last century, during the directorship of Orhan Kaya, the museum became an important institute for the cooperation between European and Turkish scientists working on disclosing the geological history of Anatolia. After his untimely death in 2002, the current director Tanju Kaya took over. As wife of Orhan Kaya and former student of Fikret Ozansoy, she carried on the tradition of hosting and collaborating with European coworkers. The 2016 meeting was very much part of that tradition and for quite a few of the participants a return to the good memories of familiar surroundings.

\section{Anatolia, a land of opportunities}

As we mentioned before, it only takes one look at a map to realise the importance of Anatolia for biogeographic studies. It is strategically positioned between three continents. It can be no coincidence that, in historical times, this was the birth ground for so many great empires, such as those of the Hittites, the Byzantines and the Ottomans or perhaps even of fabled Troy. But looking back into its geological past, it is even more intriguing. The history of the Mediterranean is complex and Anatolia plays a pivotal part in it. The first step in the forming of the sea was its closure to the east by the so-called 

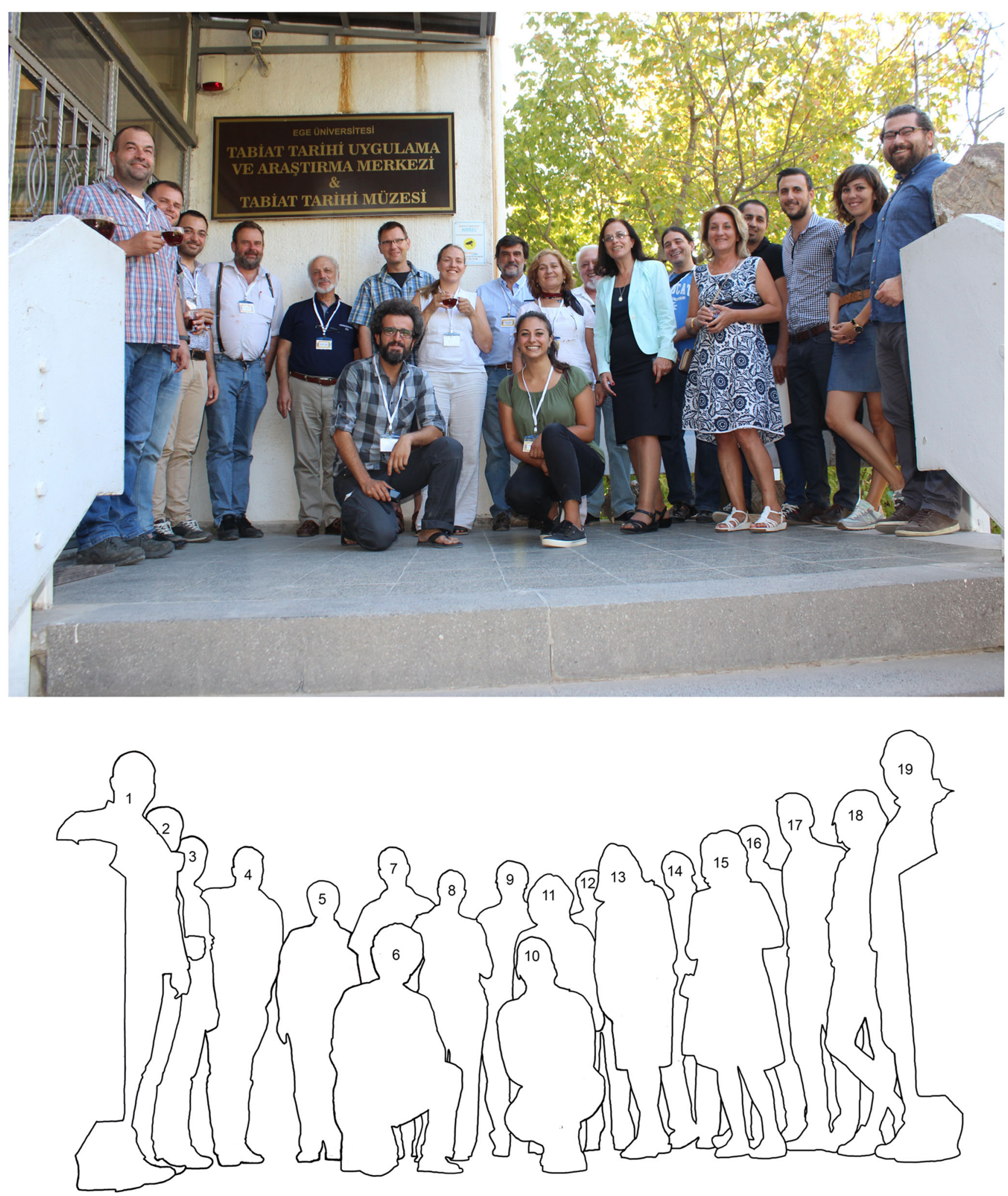

Fig. 1 The participants of the RCMNS workshop "Taking the Orient Express". 1. Peter Joniak, 2. Tunay Güner, 3. Davit Vasilyan, 4. Lars van den Hoek Ostende, 5. George Koufos, 6. Kazim Halaçlar, 7. Thomas Denk, 8. Manuela Aiglstorfer, 9. Pablo Pelaez-Campomanes,
10. Çilga Sanem Koç, 11. Ayla Sevim Erol, 12. Fikret Göktas, 13. Tanju Kaya, 14. Serdar Mayda, 15. Funda Akgün, 16. Alper Yavuz, 17. Erhan Tarhan, 18. Seval Karakütük, 19. Aytekin Tan 
Gomphotherium landbridge in the Burdigalian. This was a major event in the development of terrestrial ecosystems. Several contributions in this special issue are the results of the 2015 National Geographic expedition "Palaeogeography of mammals following the collision of the African and Eurasian plates". But the collision by the counter-clockwise movement of the African plate did much more than forming a connection with Eurasia. It is also the driving force behind the complex tectonic history of Anatolia and the formation of its many mountain ranges. The basins between those mountains provide the wealth of information on the terrestrial ecosystems of the Turkish Neogene, as remnants of its former inhabitants were preserved in the lakes and swamps to provide a rich fossil record. In this respect, Anatolia is within western Europe perhaps only rivalled by Spain. And as in Spain, the scarce vegetation in particularly central Anatolia ensures that outcrops are easily accessible and horizons can be followed over large distances.

\section{A very short history on Turkish Neogene studies}

Despite being so rich in fossil localities, palaeontological research developed relatively late in Turkey. In the 1930s, Ahmet Malik and Hamit Nafiz published the fossils of the fossil locality of Küçükçekmece, which actually lies along the route the Orient Express, close to its terminal. In those days, Turkey had particularly good connections with France, where vertebrate palaeontology thrived. Malik had studied geology with the famous French palaeontologist Charles Déperèt in Lyon. In order to be able to compare the Küçükçekmece fossils with those from other localities, Malik and Nafiz were invited to Paris by Ernest Chaput (Sen 2016). It is plausible that the two crates of Turkish fossils that they carried to Paris this way were actually transported on the Orient Express.

These early studies were directed at Thrace, the European part of Turkey. The potential of Anatolia became fully clear in the 1960s and 1970s, during a large project in which the General Directorate of Mining Research and Exploration (MTA) joined forces with German colleagues. Colloquially known as the Sickenberg project, this cooperation discovered many of the fossil localities that have since become famous names in Turkish palaeontology, including some of the renowned hominoid localities such as Paşalar. The project also provided a big impulse for palynological studies, as, certainly at the time, pollen was considered a suitable marker for the Turkish Neogene. The German palynologist Leopold Benda was greatly involved in the Turkish Neogene, but soon many Turkish palynologists would emerge, such as Funda Akgün, one of the most renowned specialists on the palynomorphs of Anatolia.

The study of larger palaeobotanical remains of Turkey started even later and took off in the 1970s and 1980s. The main pioneer was Baki Kasaplıgil, who worked on the Güvem flora. Also European scientists started working on Anatolia leaves fossils, such as the French palaeobotanists Paicheler and Blanc. Mädler and Steffens were involved in the Sickenberg project and published their findings about the same time. Notably, macrobotanical remains of Turkey are traditionally somewhat underrepresented in the published fossil record, but, as the Izmir meeting showed, there is a renewed interest of these fossils, particularly for palaeoenvironmental reconstructions.

Micromammals are currently considered the best stratigraphic markers for terrestrial sediments of the Caenozoic. Rodent fossils were collected during the Sickenberg project, but the systematic study of micromammals was relatively new at the time. In the 1990, the MTA had collaborative projects with Hans de Bruijn from Utrecht University and Şevket Şen from the Paris natural history museum. Ultimately, this would lead to a first stratigraphic scheme for the Turkish Neogene based on rodents (Ünay et al. 2003). As we noticed before, the 1990s was also the decade in which the Izmir museum became more and more active in international cooperation. Its director, Orhan Kaya, was quick to recognise that small mammal research could help resolve some of the issues that he had in his geological studies on western Anatolia. In fact, some of the contributions in this special issue are part of that legacy, based on collections he had gathered.

On the shoulders of this old generation, a new generation of researchers emerged with a keen interest in the history of Anatolia. 'Taking the Orient Express' was a meeting which featured a mixture of old and new generations and of specialists in palaeozoology and palaeobotany. And as it turned out, that was indeed the perfect mix for three days of exchange and inspiration. The task ahead of us is a daunting one. At present there is a tendency to see the fossil record of Anatolia for a given time slice as a whole, given the relatively few datapoints we have. However, we should bear in mind that the surface area of Anatolia equals that of France and Germany combined. Who travels the country nowadays, will be impressed with the variety of ecosystems within the region (Fig. 2); we must assume that this was not very different in the past. Therefore, recognising the different palaeoenvironments within Anatolia is as much a challenge as understanding the relationships between the environments of Anatolia and those elsewhere in Eurasia. Much has been done, but there is still endlessly more to be discovered before we truly understand the history of the Anatolian ecosystems and how they helped to shape the world we live in. This special issue features eight contributions, each of which represent a step closer to doing just that.

\section{Eight contributions to the history of Anatolia}

To the participants and organizers of the workshop, the meeting was a great success. But success needs to be shared and 

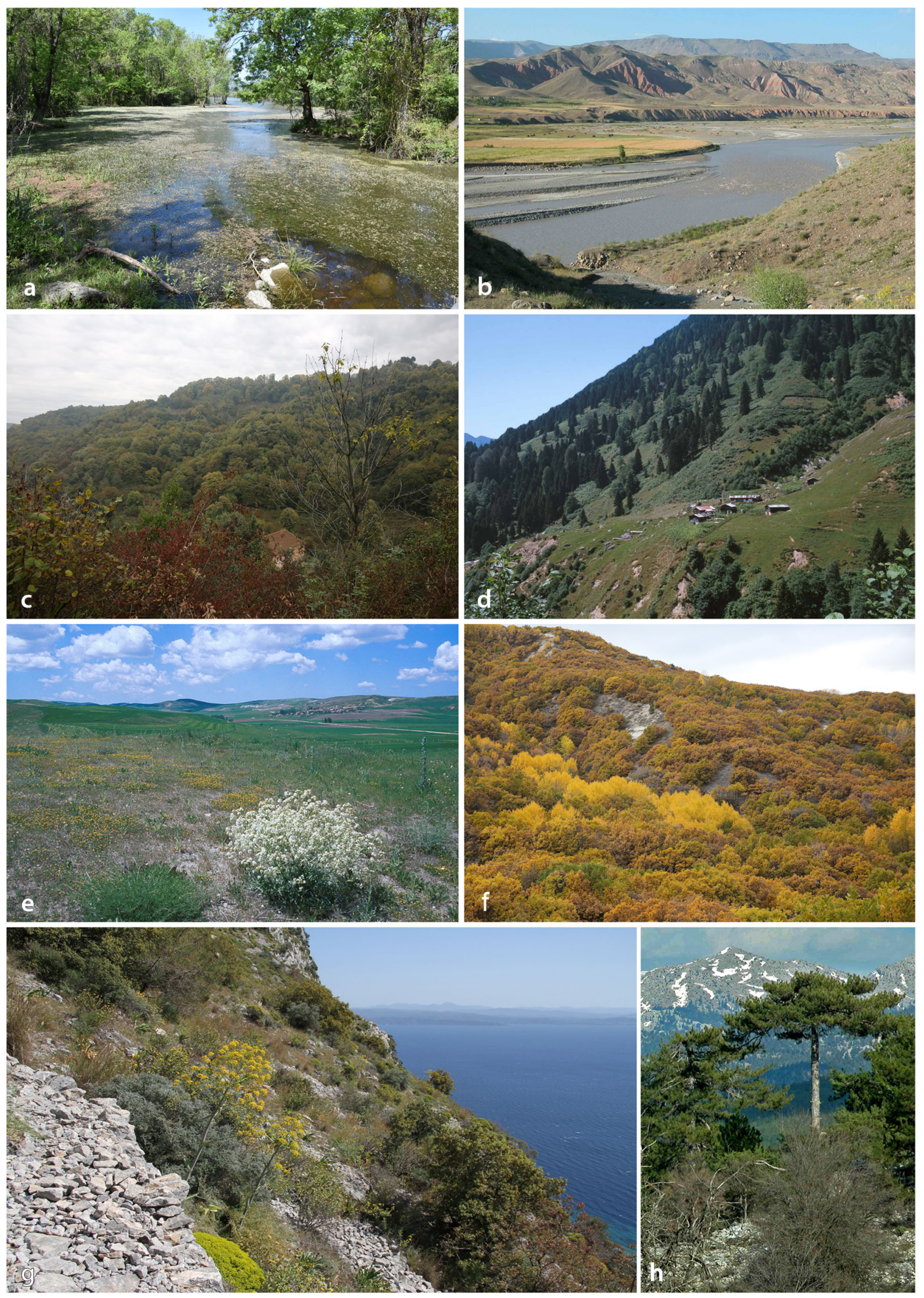
4Fig. 2 a Broadleaf deciduous floodplain forest, Kocaçay Delta, Karacabey-Bursa, NW Turkey. (Courtesy: T. Güner); b Steppe and semi-desert vegetation, Aras Valley, NE Turkey. Ecoregion: Eastern Anatolian Region, Mountain Steppe and Mountain Steppe-Grass subregions. (Courtesy: G. Pils); c Broadleaf deciduous forest, Black Sea Region. (Courtesy: T. Denk); d Mixed needleleaf evergreen - broadleaf deciduous forest, Kaçkar Dağları, NE Turkey. (Courtesy: G. Pils); e Remnant of Anatolian steppe, S of Ankara, C Turkey. (Courtesy: G. Pils); f Dry broadleaf deciduous forest, $\mathrm{N}$ of Ankara, C Turkey. (Courtesy: T. Denk); g Mediterranean shrubland, S of Milas, Bodrum, SW Turkey (Courtesy: T. Denk); h Needleleaf evergreen forest, central Taurus Mountains, S Turkey (Courtesy: G. Pils)

that is how the idea of this special issue came to be. As we mentioned above, the complicated tectonics of Anatolia are a major driving force behind the development of the Neogene terrestrial habitats of the region. Cihat Alçiçek leads a veritable army of co-authors in a contribution that shows the intricate interplay between tectonic modelling and the terrestrial fossil record (Alçiçek et al. 2019). Their research focuses on the basins of south-western Anatolia that were formed by regional crustal extension since the Tortonian. Using the fossil record to correlate between the basins, the authors show that the formation of these basins involved a second extension phase followed by dissection during the early Pleistocene. The study is not only an example of how fossils are pivotal in dating tectonic events, but also uses the complete array of fossil taxa that terrestrial environments have to offer, including ostracods, molluscs, pollen and mammals. This is very much in line with the goals of the Working Group Terrestrial Environments and accounts for the large number of specialists that contributed to the paper (Palaeobiodiversity and Palaeoenvironments 99(4) https://doi.org/10.1007/s12549019-00394-3).

One of the most conspicuous changes in the topography of Anatolia during the Miocene must have been the formation of its mountains and valleys. Whereas Alçiçek at al. discussed the formation of entire basins, the contribution of Sezgül Kayseri et al. (2019) manages to reconstruct changes in altitude within a basin. Previously, it had been assumed that the palaeotopography of the Çankiri-Çorum had not changed, but using an Integrated Plant Record vegetation analysis demonstrated higher altitudes in the north part of the basin during the latest late Miocene and early Pliocene. The analyses of the Çankiri-Çorum basin cover a large time span, from the late middle Miocene to the Pleistocene and Sezgül-Kayseri and coworkers reconstruct climatic changes during that interval using the Coexistence Approach. Their study is not only a fine example of how palynology can track vegetational changes over a prolonged period of time, but also a testimony to the rich Turkish tradition in the field (Palaeobiodiversity and Palaeoenvironments 99(4) https://doi.org/10.1007/s12549019-00383-6).

Recent advances in palynology introduced techniques that allow a far more detailed study of pollen grains leading to a more accurate identification. Obviously, this also allows for more detailed environmental reconstruction. The contribution of Johannes Bouchal (2019) is an excellent example of this new generation palynology. His study of the palynomorphs of the middle Miocene Salihpasalar mine (Yatagan Basin, SW Anatolia) features many Scanning Electron Microscopy photographs revealing the finest details of fossil pollen grains. Having such an excellent view on the morphology allows to strongly link the fossils to botanical nomenclature. This is in sharp contrast with the earliest contributions to palynomorphs in Anatolia. As we noted before, at that time palynology was mostly used as a stratigraphical tool, for which a morphological nomenclature sufficed. There was no need for identifying genera or species, nor did we yet have the advantage of modern-day pollen atlases available today. During the Izmir workshop some discussions arose about the need to translate these early studies to botanical nomenclature as the main interest of palynological studies shifted to environmental and climatic reconstructions. The paper by Bouchal makes a significant contribution to this change, as it includes a list comparing the pollen from the Yatagan Basin with morphologically similar taxa described elsewhere in Anatolia (Palaeobiodiversity and Palaeoenvironments 99(4) https:// doi.org/10.1007/s12549-018-0345-0).

Three of the four mammal papers in this special issue are related to the National Geographic Expedition "Palaeogeography of mammals following the collision of the African and Eurasian plates". The contributions of Pelaez-Campomanes et al. and Bilgin et al. are based on test samples of Orhan Kaya from the end of the last century. As the expedition team, Kaya was very much interested in the early Miocene. His finds were therefore a valuable addition to the material collected in the expedition itself.

The locality of Gördes, from which Pelaez-Campomanes et al. (2019) describe material, has meanwhile been destroyed. This is quite unfortunate, as a mere $75 \mathrm{~kg}$ of sediment yielded already sixty micromammal fossils, a richness which is rare indeed. Moreover, based on its evolutionary stage, the faunule seems to represent a time slice from local zone $\mathrm{D}$ that is not yet known from other localities and includes a new species of the cricetid Eumyarion. The test sample that was at the basis of the publication of Bilgin et al. (2019), Bornova 183, is far more modest. The importance of this faunule, however, lies in the combination with a known locality from the same formation, Sabuncubeli. The latter was published over a decade ago and the present authors included new material, increasing the faunal list with five species. Comparison of the stage of evolution of the test sample and the old fauna suggests that a respectable time period is represented in the Sabuncubeli Formation, covering most of local zone D (Palaeobiodiversity and Palaeoenvironments 99(4) https://doi.org/10.1007/s12549018-0346-z and https://doi.org/10.1007/s12549-019-003952). 
A similar situation as the Sabuncubeli faunas is discussed in Joniak et al. (2019) They visited during the National Geographic expedition the old lignite mine Harami, from which two assemblages were described at the beginning of the 1990s. The authors add two more local zone $\mathrm{C}$ assemblages, Harami 4 and 5. The latter is a small faunule from the top of the mine, but, as in the paper by Bilgin et al., this is enough to demonstrate that a sizeable amount of time is represented in the section. In addition, the authors discuss for the first time the Harami assemblages in terms of the abundance of the various components. This offers a clearer picture of the faunal differences between Harami 1 and 4 on one side, and Harami 3 on the other. In palaeoenvironmental terms, the former seems to represent a swamp, whereas the latter is considered more indicative of a marshy environment (Palaeobiodiversity and Palaeoenvironments 99(4) https:// doi.org/10.1007/s12549-018-0349-9).

The fourth mammal contribution in this issue deals with the insectivore assemblage of the MN 2 locality of Gökler. The locality had yielded various new species of rodent. In terms of faunal composition, the insectivores yielded no surprises, as it comprises the familiar species of the early Miocene of Anatolia. Looking at the abundances, however, the rarity of the talpid Theratiskos stands out and Van den Hoek Ostende et al. (2019) suggest that this may be related to differences between the environments in central Anatolia and elsewhere in the region (Palaeobiodiversity and Palaeoenvironments 99(4) https://doi.org/10.1007/s12549-019-00396-1).

Also the final distribution of the special issue deals with the early Miocene. In fact, many of the localities discussed in the mammal papers, as Kilçak, Harami and Keseköy feature prominently in the paper by Vasylian et al. (2019), describing the ectothermic vertebrates of the sites. The paper includes the first fossil occurrences in Anatolia for several genera and for several others the oldest known record in the world. Reptiles and amphibians represent excellent palaeoenvironmental markers. Notably, the reconstruction of the environments of the Harami assemblages parallels the conclusions based on mammals in the paper by Joniak et al. (Palaeobiodiversity and Palaeoenvironments 99(4) https://doi.org/10.1007/s12549019-00405-3).

\section{The road ahead}

For the old travellers to Anatolia, the Orient Express was only the first part of the journey. Reading the contributions in the special issue, the reader may be impressed by the large amount of work done by the present authors and by the predecessors. But who carefully reads, will note that each contribution also presents questions for future research. Not all of the interesting lectures during the meeting led to an article in this special issue. In this respect, we certainly need to mention the renaissance in the study of macrobotanical fossils. And not forget the great work done on the Miocene hominoid localities of Anatolia.

We are at the brink of further advances with a new generation of European and Turkish researchers being drawn to the unresolved questions that Anatolia has to offer. We cannot claim to be the first part of the journey, as we all find a basis in the work of the true pioneers. But in the end, this special issue is only another station on a scientific journey. And there is still a lot of track ahead of us.

Acknowledgements First of all, we wish to thank all the participants to the Izmir meeting and the contributors to this special issue. Both meeting and issue turned out to be very interesting and informative. The success of the meeting was certainly in part thanks to the warm hospitality of the Natural History Museum of EGE University. In particular, we wish to thank Hakan, Özgur, Ayse, Eyüp and Yasemin for making the coffee and lunch breaks such a memorable part of the experience. We are grateful to rector Prof. Dr. Necdet Budak and dean Prof. Dr. Ihsan Yasa for the continuous support of the palaeontological research at EGE university. We thank Çilga Sanem Koç for her assistance in finding data on the history of macrobotanical remains of Anatolia. Gerhard Pils, Thomas Denk and Tuncay Güner provided the photographs and caption for Fig. 2. Finally, our gratitude goes to the editors of Palaeobiodiversity and Palaeoenvironments for providing a platform for sharing our results, with a special thanks to Sinje Weber for her patience and guidance on this journey.

\section{Compliance with ethical standards}

Conflict of interest The authors declare that they have no conflict of interest.

\section{Reference}

Sen, S. (2016). Historical background. In S. Sen (Ed.), Late Miocene mammal locality of Küçükçekmece, European Turkey. Geodiversitas, 38(2), 153-173.

Ünay, E., Bruijn, H. de, \& Saraç, G. (2003). A preliminary zonation of the continental Neogene of Anatolia based on rodents. In J.W.F. Reumer, \& W. Wessels (Eds.), Distribution and migration of tertiary mammals in Eurasia. A volume in honour of Hans de Bruijn. Deinsea, 10, 539-547.

Publisher's note Springer Nature remains neutral with regard to jurisdictional claims in published maps and institutional affiliations. 